DE DE GRUYTER

OPEN

G

Germinal Isern

Clark University
Journal of Intercultural Management

Vol. 6, No. 1, January 2014, pp. 5-16

DOI 10.2478/joim-2014-0001

\title{
Intercultural Communication and Management Factors and Their Impact to the Process of Global Software Development for Virtual and Non-Virtual Teams
}

\begin{abstract}
This position paper presents the factors involved in the successful software development and what is the impact of some methodologies like Agile in this process. Global software development projects may be a total success or an anticipated disaster for simple reasons that usually have nothing to do with the technology involved, with the time differences, or the product being built, but because of subtle intercultural factors. How do the language, the race, the gender, the religion, and the location affects the software development process from analysis and design to implementation, testing and maintenance? Do all these factors impact in the same way if we are working with a local team, and offshore development team or even a global virtual team? Is any specific software development methodology better suited for your particular case? How could you decide what's the better approach? What will be the results and what our goals? The issues at stake are not superficial matters of the ways how people dress, or how clear do they speak in our local language, or what they like to eat, or their small daily behaviors, but are based in the fundamental differences in the systems of values that govern our lives. So institutions, corporations and global companies have to raise the level of awareness of their employees worldwide on the cultural differences, through various programs for intercultural or diversity training. But this poor model of cultural awareness is not enough to overcome some of the obstacles that intercultural differences bring to the table. So this paper will list and describe this important intercultural factors that directly impact in the software development process and how certain software development methodologies could be used in order to have a more systematic look or set of guidelines that would allow the team managers to evaluate and to decide how the
\end{abstract}


use of each one of these software development methodologies for local teams, non local teams and virtual teams will affect positively or negatively the outcomes of software development practices.

Key words: intercultural communication, software development, Virtual and Non-Virtual Teams

\section{Introduction}

During the last decade and a half the outsourcing or off-shoring phenomenon has center the attention for the Global Software Development process, in particular in the first years of that period of time with the successes of Indian software companies and later with the appearance of new players like Brazil, China, Eastern European countries, etc. Some studies estimate that more than half a million jobs would go from North America to India by 2015 and lately Indian companies had outsourced themselves to some other countries. Even emblematic Indian IT offshore enterprises like the Call Centers now are moving to countries like the Philippines. IT projects are the second largest class of outsourced activities after call centers.

There is plenty of research related to labor issues, geopolitics aspects, economical factors and IT infrastructure but not too much about specific issues associated with the intercultural factors involved in the Global Software Development and even less when we have to deal with virtual teams.

Globalization has quickly become a common and significant practice across a multitude of industries like manufacturing, automotive, financial, retail, and other sectors. High-speed communication networks, global opportunities, and other technological and social advancements have enabled big and small institutions to extend their reach around the world.

Software teams are increasingly distributed around the world, collaborating both internally across the company and externally with partner companies, subsidiaries, and outsourcing service providers. Since the first teams were created large companies have made changes in how they manage distributed teams and now virtual international cross-cultural teams.

We'll try to describe the intercultural factors involved in this process and how each Software Development model might contribute to minimize the undesirable consequences. We'll start describing the market trends in Global Software Development, the different model for Software Development and finally the impact. In the age of globalization the workplace is becoming increasingly cross-culturally integrated making understanding and expertise in cross-cultural communication more crucial for executives, business leaders, workplace managers, and standard employees.

In order to get a deeper understanding of and acquire skills in intercultural encounters at the workplace, those engaged in it must gain practical knowledge 
of the factors that impact cross-cultural communication and how does factors impact in different software development models. According to experts in the field of intercultural communication, some of those factors include:

1. Cultural Identity

2. Racial Identity

3. Ethnic Identity

4. Gender Role Identity

5. Individual Personality

6. Social Class Identity

7. Age Identity

8. Roles Identity

1. The Cultural Identity Factor

Culture is the values, attitudes, and ways of doing things a person learns during the socialization process in the particular place where they were brought up as a child. The cultural identity factor impacts cross-cultural communication because the norms and practices a person acquires and practices in their country and local community will be different from and clash with the norms and practices of co-workers brought up in a different countries or societies.

2. The Racial Identity Factor

The racial identity factor refers to how one's conscious membership in a particular race affects how they interact with folks in the workplace who come from different cultures.

3. The Ethnic Identity Factor

The ethnic identity factor highlights the role ethnicity plays in how two coworkers from different cultures interact with one another. In the United States, white European Americans are less likely to take their ethnicity into account when communicating, but members of other ethnic groups such as African Americans, Latin Americans, and Asian Americans are more likely to consider their ethnic backgrounds in the communication process.

4. The Gender Role Identity Factor

This means that communication between members of different cultures is affected by how different societies view the roles of men and women.

5. The Individual Identity Factor

This means that how a person communicates with others from other cultures depends on their own unique personality traits and how they esteem themselves. 


\section{The Social Class Identity Factor}

The social identity factor refers to the level of society that person was born into or references when determining who they want to be and how they will act accordingly.

\section{The Age Identity Factor}

The age identity factor refers to how members of different age groups interact with one another. In old terms this might be thought of in terms of the generation gap. More hierarchical cultures like China, Thailand, and Cambodia pay great deference and respect to their elders and take their elders' opinions into account when making life-changing decisions. Cultures like the United States are less mindful of their elders and less likely to take their advice into account when making important decisions. Such attitudes towards age cause the age identity factor to impact intercultural communication at the workplace.

\section{The Roles Identity Factor}

The roles identity factor refers to the different roles a person plays in his or her life including their roles as a husband or wife, father, mother or child, employer or employee and so forth. How two members of a workforce from two different cultures view these various roles influences how they will interact with their fellow colleague or counterpart.

\section{Frame of reference}

Global Software Development Market Tendencies

Institutions continue to expand globally, distributing their software development teams around all the continents through a variety of means, including offshoring, acquiring, partnering, and outsourcing. The evolution seen in this market is summarized in the following figure.

Figure 1: Tendencies in outsourcing /offshore Global Software Development

Evolution from "It's cheaper in India" to "Talent is everywhere"

\begin{tabular}{|l|l|}
\hline Transitioning from... & Transitioning to \\
\hline Offshore labor mainly in India & $\begin{array}{l}\text { Labor spread un multiple place around the } \\
\text { world }\end{array}$ \\
\hline Cheaper labor abroad than in homeland & $\begin{array}{l}\text { Offshore provides affordable access to a larger } \\
\text { pool of talent and state of the art technologies }\end{array}$ \\
\hline Mainly oriented to maintenance tasks & New development life cycle, design and testing \\
\hline
\end{tabular}




\begin{tabular}{|l|l|}
\hline $\begin{array}{l}\text { Predominantly programming at the techni- } \\
\text { cal level }\end{array}$ & $\begin{array}{l}\text { Services Oriented Architecture (SOA), Busi- } \\
\text { ness Process Outsourcing, Consulting, Infra- } \\
\text { structure }\end{array}$ \\
\hline Global delivery is specialty & Global delivery is a standard \\
\hline
\end{tabular}

Source: Future of It services, Bernstein Research May 22, 2006, Gartner on outsourcing. Future of outsourcing, Forrester Research Oct 242006.

A lot of the initial moves into the global market involved transferring work to a single site, frequently in India, later often in China or Eastern Europe, now almost everywhere. Cost was typically the primary motivator - decisions to transfer work were driven by the availability of skilled labor at rates much cheaper than in the United States and Western Europe, and in the case of India with respect to software development also with a lot of prepared and talented software developers.

Now enterprises are establishing more and more development centers in multiple locations across the world. While cost savings remains a factor, with many companies maintaining lower-cost centers in Asia, South America and Central Europe, other motivators have also come into play:

- With more available resources, companies can staff projects better and select talents from more than one site.

- With teams working in different time zones or with virtual teams sometimes spread across the world, companies can accomplish a longer workday with what is often called "follow the sun" development; even this will create a lot of the cultural communications problems that we will address later.

- Eastern teams handoff work at the end of their day to teams further west who are just beginning their day.

Outsourcing has become more strategic and in the last years we are actually moving towards a right-sourcing model assigning tasks to the right people with the right skills, regardless of where those people are located geographically, and regardless of their culture, their first language, their traditions, their religion, their gender, their race, etc.

Outsourcing is no longer just for maintenance; the type of software development work that is outsourced is also changing. Maintenance of existing applications was once the dominant outsourcing practice in software development. Application testing is now growing rapidly, followed by innovation of new application technologies or components. Some companies that consider application development a supporting service outsource all but requirements and acceptance testing. The influence of services-oriented architecture (SOA) has led to the identification and distribution of specific services, whether technical (code) or business. This is new role is a lot more complex and demands 
stronger team, better communication and a better understanding of the cultural differences.

Other areas of growth outside of software development include businessprocess outsourcing (BPO). An excellent example of this is Tata Consulting Services (TCS) in India, approximately 50 percent of their revenue came from consulting, BPO, and infrastructure services; first-time application development made up less than half of their revenue. TCS itself outsources work from India to other countries.

Evolution in organizational distribution

The structural organization of the companies is changing in order to mirror the approaches to product delivery. Many international organizations initially assigned project ownership by locality or region, making each location or branch responsible for the deployment of its own project, and sites worked independently.

As global organizations extend their presence across the world, multiple sites become a "team of teams" contributing to a global delivery chain. Each team may own a module or element they deliver for integration with other locations, regions or companies, culminating in a final application. Those teams may be part of the same organization, division, or company, or be part of different ones.

The distribution is due in large part to acquisitions and mergers. In industries such as telecom, high technology, banking and financial services, corporations acquire market share, technologies, or market entry by acquisition, rather than by internal development.

\section{Culture, cultural theories and intercultural factors, or variables}

Culture could be defined as the integrated pattern of knowledge, belief, and behavior that depends upon the capacity for learning and transmitting knowledge to succeeding generations. Culture is thelearned values and behaviors shared by a group of people and play a vital role in how a person performs his or her work based on individual patterns of thinking, feeling, and acting. Culture has visible attributes like dining, clothing, religious rituals, architectures, or sports while invisible attributes comprise of orientations to environment, time, communication, space, power, individualism, competitiveness, structure, and thinking. Several theories have been proposed to categorize cultural differences. As the primary source of intercultural factors, we used the works of E. T. Hall [Hall, 1976], G. Hofstede [Hofstede, 1997., Hofstede, Pedersen, Hofstede, 2002, Fiske, 1991, Fiske, 1992, pp. 689-723,] and F. Trompenaars \& Charles Hampden-Turner [Trompenaars, Hampden-Turner, 1997]. 


\subsection{Hofstede's Cultural Dimensions}

Hofstede conducted a study for IBM employees in 40 countries to find the impact of culture in workplaces. He identified 5 cultural dimensions; they are Power Distance (PDI), Individualism/Collectivism (IDV), Uncertainty Avoidance (UAI), Masculinity/Femininity (MAS), Short-term or Longterm Orientation (LTO). These dimensions give insight to different national cultures for effective interaction with people from different countries. If these dimensions are understood and applied appropriately it should reduce the level of frustration, anxiety, and concern among team members and help in effective communication.

\subsection{E. T. Hall's Cultural Factors}

One of the pioneers of this field E.T. Hall, based on anthropological analyses identified key cultural factors. These are classified into High Context and Low Context based on time and space. Hall also looked at the way cultures handle time - Mono-chronic cultures versus Poly-chronic cultures.

\subsection{Trompenaars \& Hampden-Turner}

They state that the purpose of national culture is to provide answers and solutions to challenges faced by individuals and they have defined a different set of discriminating factors based on the studies they have done as part of a consulting practice for large multinational companies. They too distinguish several dimensions:
a. Universalism vs. Particularism
b. Individualism vs. Communitarianism
c. Neutral vs. Emotional
d. Specific vs. Diffuse
e. Achievement vs. Ascription (attitude toward titles, degrees...)
f. Sequential vs. Synchronic cultures
g. Internal vs. External control.

They have explained to international managers how to build the skills, sensitivity, and cultural awareness needed to establish and sustain management effectiveness across cultural borders.

\subsection{Fiske}

Fiske described four forms of socialite

a. CS: communal sharing: do people treat all members of a category as equivalent.

b. AR: authority ranking: do people attend to their positions in a linear ordering. 
c. EM - equality matching: how people keep track of the imbalances among them.

d. MP: market pricing, how people orient to ratio values.

All these theories collaborate with managers in the task to gain insight into culture in different ways. Hofstede's cultural dimensions help managers to recognize individual and group behaviors in different countries. E.T. Hall's adds the dimensions based in context concept of time and space. Trompenaars and Hampden-Turner have a contradict Hofstede's cultural dimensions approach because they view culture as process and propose that 'culture is the way in which a group of people solve problems and reconcile dilemmas'. Hofstede analyses the variables of national cultures, whereas Trompenaars and Hampden-Turner are involved in the processes of cultural creation. Many other researchers such as Philippe d'Iribarne [D'Iribarne, 2009] have the same approach as Hall but with an ethnographic method for sense-making. Vaara [Vaara, 2000, pp. 81-110] has broadened these cultural studies with an epistemological approach where they state that culture and cultural differences exist only when people become aware of it in their social interactions.

\section{Software Engineering Development Models}

The software engineering practices that are basically affected are the ones that involve human-to-human communication, either at the time they are performed, or later, in their consequences. But if we close review in what consist the whole software development process we will conclude that humanto-human communications is covering most of what we do in software. On the other hand a lot of the type of software processes used in global outsourcing projects, does not involves too much human interaction. We can certainly look at how these processes are themselves tainted by the cultural backgrounds of their authors.

\subsection{Agile}

Agile software development is a group of software development methods based on iterative and incremental development, where requirements and solutions evolve through collaboration between self-organizing, crossfunctional teams. It promotes adaptive planning, evolutionary development and delivery, a time-boxed iterative approach, and encourages rapid and flexible response to change. It is a conceptual framework that promotes foreseen interactions throughout the development cycle. The Agile Manifesto [Agile Alliance, 2001] introduced the term in 2001. Incremental software development methods have been traced back to 1957. In 1974, a paper by was introduced an adaptive software development process. 
So-called lightweight agile software development methods evolved in the mid-1990s as a reaction against the heavyweight waterfall-oriented methods, which were characterized by their critics as being heavily regulated, regimented, micromanaged and overly incremental approaches to development.

Proponents of lightweight agile methods contend that they are a return to development practices that were present early in the history of software development.

Early implementations of agile methods include Rational Unified Process (1994), Scrum (1995), Crystal Clear, Extreme Programming (1996), Adaptive Software Development, Feature Driven Development (1997), and Dynamic Systems Development Method (DSDM) (1995). These are now collectively referred to as agile methodologies, after the Agile Manifesto was published in 2001.

To find more likely candidates we may look at the agile set of methods and practices [Agile Alliance, 2001, Beck, 2000.], which precisely have come to rely much more on direct person-to-person interaction and less on "follow the plan", "fill the template", and "check the boxes" approaches. The twelve XP practices and Scrum [Schwaber, Beedle, 2002] constitute a good representative set. Unfortunately these practices are often confined within a single, co-located (and therefore often culturally homogeneous) team and they are not visible at the hinges between two cultures in global projects.

\section{Impacts}

For example let's review the principles of Agile described in the Agile Manifesto and let describe soma cases in which affect positive and some in a negative way. The Agile Manifesto is based on twelve principles:

1. Customer satisfaction by rapid delivery of useful software

2. Welcome changing requirements, even late in development

3. Working software is delivered frequently (weeks rather than months)

4. Working software is the principal measure of progress

5. Sustainable development, able to maintain a constant pace

6. Close, daily cooperation between business people and developers

7. Face-to-face conversation is the best form of communication (co-location)

8. Projects are built around motivated individuals, who should be trusted

9. Continuous attention to technical excellence and good design

10.Simplicity-the art of maximizing the amount of work not done-is essential

11.Self-organizing teams

12.Regular adaptation to changing circumstances

For example the point 6 related to cooperation between developers might be seriously affected when working with virtual teams and in the case of non- 
virtual teams even more in connection with gender and culture differences. Point 8 might be very clearly affected by language and 8 by social and cultural motivations. Points 11 and 12 also differ totally between different cultures (eastern civilization vs. western civilization). We will try including some previous research to describe certain examples.

\subsection{Reviews and chronicity}

Laroche [Laroche, 2002] identified some impacts. One impact is what he calls "time is up", in this one Mono-chronic people tend to end the meeting at the scheduled end-time, Poly-chronic time people tend to end when the conversation runs out of steam and rarely at the scheduled end time. When they work together, poly-chronic people may think that the meeting ends abruptly, before they have a chance to say their whole piece. In contrast, M-time people may consider that meetings go on past the point of effectiveness. Agile meetings are frequents and concise but it is very important to reach consensus and draw a plan.

Laroche also identifies several other issues like for example agenda either implicit or explicit. This is very common and we can find it within countries or regions that limit with others with historical issues, like French and Spaniards, Chileans and Peruvians, Canadians from Quebec and Canadians from Ontario. There are some very famous cases that are studied in Software Engineering courses like the Airbus integration management.

\subsection{Power distance and Management Requirement}

One of the biggest issues is related with the team coordination and the hierarchical forms of communication. Thanasankit and Corbitt studied some factors of power distance and uncertainty in Thai culture [Thanasankit, Corbitt, 2000]. These factors contribute towards hierarchical forms of communication and decision-making processes in Thailand, especially during Requirements Engineering. Their research shows a much longer time for the decision-making, as every stage during Requirements Engineering needs to be reported to management for final decisions. The tall structure of Thai organizations also contributes to a bureaucratic, and longer decision-making process during the software development process, this elongation can seriously affect the performance of a virtual team. In eliciting/validating/prioritizing requirements, often who said what and where that person seem to appear in the hierarchy is more important than the needs or the technical issues.

\section{Conclusions and Future Work}

This was a position paper just to describe the factors and the software development methods to study so there is not much to conclude, this early 
in our study. But we set the parameters for the future study that we hope will produce a systematic approach in order to configure and enact software engineering processes IT outsourcing and specifically for the global software development, being able to respect cultures, nations and groups involved and reaching the maximum performance.

\section{References}

Agile Alliance, Manifesto for Agile Software Development, 2001, http://agilemanifesto. org/

Beck K., Extreme Programming Explained: Embrace Change. Boston: Addison-Wesley, 2000.

Carmel E., Global Software Teams: Collaborating Across Borders and Time Zones. Upper Saddle River, NJ: Prentice Hall, 1999.

Coggins E., 8 Factors That Impact Cross-Cultural Communication in the Workplace and Beyond. Hubpages.

D'Iribarne P., 2009, Conceptualizing national cultures: an anthropological perspectivehttp://inderscience.metapress.com/app/home/contribution.

Fiske A. P., Structures of Social Life: The Four Elementary Forms of Human Relations. New York: Free Press (Macmillan), 1991.

Gopal A., Mukhopadhyay T., Krishnan M. S., "The role of software processes and communication in offshore software development", Commun. ACM, vol. 45, pp. 193-200, 2002.

Hall E. T., Beyond culture. New York: Anchor Books/Doubleday, 1976.

Hofstede G. J., Pedersen P. B., Hofstede G., Exploring culture; exercises, stories and synthetic cultures. Yarmouth, Maine, USA: Intercultural Press, 2002.

Hofstede G., Culture and organizations-Software of the mind. McGraw-Hill, 1997.

Hofstede G., Culture's consequences. Beverly Hills, CA: Sage, 1980.

Karolak D., Global Software Development: Managing Virtual Teams and Environments. NY: Wiley, 1998.

Kruchten P. B., The Rational Unified Process: An Introduction, 3 ed. Boston: AddisonWesley, 2004.

Kruchten P., Analyzing Intercultural Factors Affecting Global Software Development - A Position Paper.

Laroche L., Managing Cultural Diversity in Technical Professions. ButterworthHeinemann, 2002.

Richardson I., Deshpande S., Casey V., Beecham S., Culture in Global Software development - a Weakness or Strength?

Schwaber K., Beedle M., Agile Software Development with SCRUM. Upper Saddle River, NJ: Prentice-Hall, 2002. 
Thanasankit T., Corbitt B. J., "Thai Culture and Communication of Decision Making Processes in Requirements Engineering”, Proceeding of CATAC'00 Cultural Attitudes Towards Technology and Communication, Perth, 2000.

Trompenaars F., Hampden-Turner C., Riding The Waves of Culture, 2 ed. New York: McGraw-Hill Trade, 1997.

Vaara E., 2000, Constructions of Cultural Differences in Post merger Change Processes: A Sense making Perspective on Finnish-Swedish Cases, Man@gement, 32, p.81-110. 